\title{
A CONTRIBUIÇÃO DA ESCOLA NO PREPARO DOS JOVENS DO FUTURO: A PROPOSTA DO PROJETO DE VIDA DAS ESCOLAS DO PEI
}

\author{
Maluy Delgado da Silva ${ }^{2}$ \\ Vladimir Fernandes ${ }^{3}$
}

RESUMO: Este artigo aborda a proposta do Projeto de vida, eixo estruturante das escolas do Programa de Ensino Integral (PEI). O Programa de Ensino Integral é uma das modalidades de escola de tempo expandido oferecido pela Secretaria de Educação do Estado de São Paulo, foi concebido tendo-se em conta as necessidades e os desafios encontrados na formação do jovem em busca de uma educação de qualidade. Nesta perspectiva o PEI tem como missão ser um núcleo de formação discente, tendo o compromisso de atuar na preparação integral dos jovens e possibilitar que eles se tornem autônomos solidários e competentes. O Projeto de Vida é uma disciplina da parte diversificada do currículo, que faz parte da metodologia de projetos das escolas do PEI. A construção de um Projeto de Vida pretende contribuir para o engajamento dos jovens nos estudos e ajudá-los nas escolhas que farão para o seu futuro. Refere-se a uma oportunidade fundamental para que o jovem possa refletir e imaginar o futuro que pretende ter, é um percurso entre o querer ser e o ser. Nesse processo, a escola oferece ensinamentos, aprendizagens, vivências e apoio para que os estudantes se conheçam melhor, adquiram conhecimentos, habilidades e competências, assim, tenham condições de caminhar na direção do objetivo traçado. Refletir como se constitui este processo se torna extremamente relevante para o debate educacional e social. Dessa forma, este artigo apresenta e discute como as escolas do PEI desenvolvem o Projeto de Vida de seus alunos, quais são os pressupostos teóricos e as ações que viabilizam este trabalho e, também, apresenta alguns dos resultados alcançados, assim como, os limites e as possiblidades deste tipo de proposta educativa.

Palavras-chaves: Educação. Escolas do PEI. Projeto de Vida.

ABSTRACT: This article addresses the proposal of the Life Project, a structuring axis of the schools of the Integral Education Program (PEI). The Comprehensive Education

\footnotetext{
${ }^{I}$ Este artigo tem como base a Pesquisa de Iniciação Cientifica, com título homônimo, realizada por Maluy Delgado da Silva no ano de 2020, na Universidade Paulista UNIP, com financiamento pela Vice-Reitoria de Pós-Graduação e Pesquisa da UNIP, e orientação do Prof. Dr. Vladimir Fernandes. A pesquisa obteve menção honrosa no XXII Encontro de Iniciação Científica UNIP/PIBIC-CNPq, em novembro de 2020.

2 Graduada em Pedagogia pela Universidade Paulista, cursando especialização em Psicopedagogia e Neurociência pela Universidade Paulista. Educadora no $3^{\text {o }}$ Ano do Ensino Fundamental na Instituição de Ensino Colégio Anglo Morumbi.E-mail: maluy.potter@hotmail.com.

${ }^{3}$ Doutor em Educação pela FE-USP, mestre em Filosofia pela PUC-SP, especialista em Sociologia e História do Trabalho pela FSA. É docente titular de Filosofia na Universidade Paulista e Pesquisador do Programa Individual de Pesquisa para Docentes da UNIP. Membro do Grupo de Pesquisa "Políticas Públicas, Gestão e Formação de Professores" (UNIP-CNPq).E-mail: profvladiı@gmail.com.
} 
Program is one of the extended-time school modalities offered by the São Paulo State Department of Education, it was design taking into account the needs and challenges encountered in training young people in search of quality education. In this perspective, the PEI's mission is to be a nucleus of student training, having the commitment to act in the integral preparation of young people and enable them to become autonomous, solidary and competent. The Life Project is a discipline of the diversified part of the curriculum, which is part of the project methodology of the PEI schools. The construction of a Life Project aims to contribute to the engagement of young people in their studies and help them in the choices they will make for their future. It refers to a fundamental opportunity for young people to reflect and imagine the future they intend to have, it is a journey between wanting to be and being. In this process, the school offers teachings, learning, experiences and support so that students get to know each other better, acquire knowledge, skills and competences, thus being able to walk towards the goal set. Reflecting how this process was constitute becomes extremely relevant to the educational and social debate. Thus, this article presents and discusses how the PEI schools develop their students' Life Project, what are the theoretical assumptions and actions that make this work feasible, and presents some of the results achieved, as well as the limits and the possibilities of this type of educational proposal.

Keywords: Education. FLS Schools. Life Project.

\section{INTRODUÇÃO}

Com o propósito de aperfeiçoamento das Políticas Públicas implantadas em São Paulo nas últimas décadas, houve a necessidade de um novo modelo escolar, tendo em vista à defasagem de aprendizagem dos alunos e da exigência do contexto sócio-político, que necessitava progressivamente da ampliação de oportunidades educacionais. Este cenário indica cada vez mais, a emergência de repensar o atual modelo de escola e redesenhar o papel que a mesma deve ter para a vida e para o desenvolvimento do jovem que se quer formar para o futuro. Sendo assim, a Secretaria de Estado da Educação de São Paulo, propôs a implantação de uma política educacional redefinindo o papel da escola, concebendo-a como uma instituição democrática, inclusiva e com responsabilidade de promover a permanência e o sucesso de toda a sua população estudantil. Dessa forma, a Secretaria da Educação do Estado de São Paulo entendeu como “[... ] urgente a necessidade e a responsabilidade de garantir a permanência e o sucesso dos estudantes na escola, por meio de ações que contribuam para a inclusão social de adolescentes e jovens na sua formação como cidadãos" (QUARESMA, 2015, p. 43). 
Neste contexto foi instituído o Programa de Ensino Integral (PEI), regulamentado pela Lei № I.I64, de 4 de janeiro de 2012, alterada pela Lei Complementar №‥191, de 28 de dezembro de 2012. Fundamentado no relatório da UNESCO na Comissão Internacional sobre Educação para o Século XXI (DELORS, 1999) e, também, na Lei de Diretrizes e Bases (LDB 9394/96) que prevê a ampliação da jornada escolar como uma finalidade de democratizar as oportunidades de aprendizagem.

As concepções do Programa de Ensino Integral implicam mudanças na abordagem pedagógica, no conteúdo do currículo e na carga horaria de ensino oferecido. Procedendo para garantir um salto de qualidade na educação dos jovens, visto que, a ampliação da jornada escolar torna-se uma estratégia fundamental para viabilizar metodologias que deverão elevar os indicadores de aprendizagem dos estudantes em todas as suas dimensões. Ampliar o tempo de permanência na escola equivale a criar novas condições de ensino e concretizar o conceito de formação integral, desenvolvendo as competências e habilidades humanas em seus diferentes aspectos: cognitivos, afetivos e socioculturais.

O Programa de Ensino Integral é uma das modalidades de escola de tempo expandido oferecido pela Secretaria de Educação do Estado de São Paulo, e de acordo com as Diretrizes do Programa tem como missão ser um núcleo de formação de jovens, “[...] primando pela excelência na formação acadêmica, pelo apoio integral aos seus Projetos de Vida, pelo aprimoramento do aluno como pessoa, pela formação ética e pelo desenvolvimento da autonomia intelectual e do pensamento crítico". Para tanto, o programa se apoia em valores que consiste na [...] valorização da educação pública pela oferta de um ensino de qualidade; valorização dos educadores; gestão escolar democrática e responsável; espírito de equipe e cooperação [...].” (SÃO PAULO - ESTADO, DIRETRIZES DO PROGRAMA ENSINO INTEGRAL, 2012, p. 35 e 36).

O Programa de Ensino Integral conta com um conjunto de metodologias que compõe a parte diversificada do currículo, as escolas que participam do programa possuem na sua matriz curricular disciplinas e atividades de: Protagonismo Juvenil; Clubes Juvenis; Projeto de Vida; Acolhimento; Turmas de Nivelamento; Disciplinas Eletivas; Orientação de Estudos; Preparação Acadêmica e para o Mundo do Trabalho, as quais contribuem para o pleno desenvolvimento de seus estudantes, por meio de uma formação ética e cidadã, 
assegurando a formação de jovens autônomos, solidários e competentes, conforme apresentado na Lei complementar № I.I64:

Art.2 I. Ensino Integral - tem como objetivo a formação de indivíduos
autônomos, solidários e competentes, com conhecimentos, valores e habilidades
dirigidas ao pleno desenvolvimento da pessoa humana e seu preparo para o
exercício da cidadania sua qualificação para o trabalho, [...] podendo o Ensino
Integral ser oferecido em unidades escolares de ensino fundamental e/ou médio.
(SÃO PAULO - ESTADO, LEI COMPLEMENTAR № I.I64, 20I2).

Observa-se que não apenas o desenho curricular dessas escolas que é diferenciado, mas também a sua metodologia, o modelo pedagógico e o de gestão escolar. A construção do Modelo Pedagógico do PEI é baseada em quatro princípios educativos e norteadores do Programa, as quais são fundamentais para a orientação e a construção das metodologias, são estes: Os Quatro Pilares da Educação para o Século XXI; A Educação Interdimensional; A Pedagogia da Presença; e o Protagonismo Juvenil.

Os Quatro Pilares da Educação elaborados pela Comissão Internacional sobre Educação para o Século XXI consiste em organizar a educação em torno de quatro aprendizagens fundamentais, denominados como pilares do conhecimento, são estes: aprender a conhecer, isto é, adquirir os instrumentos de compreensão; aprender a fazer, poder agir sobre o meio envolvente; aprender a viver junto, participar e cooperar com os outros e por último o aprender a ser, via essencial que integra as três anteriores, em múltiplos pontos de contato, de relacionamento e de permuta. (DELORS et. al., 2003, p. 9o).

A Educação Interdimensional complementa os Quatro Pilares da Educação, uma vez que busca uma integração equilibrada das diversas dimensões humanas. Essa proposta, conforme Costa (2008), considera que o desenvolvimento humano se sustenta a partir de quatro dimensões, sendo elas: o logos (dimensão do pensamento); o pathos (dimensão do sentimento); o mythos (dimensão do mistério da vida e da morte) e por fim o eros (dimensão do desejo).

A Pedagogia da Presença é um princípio norteador do programa, pois consiste na presença afirmativa por parte dos docentes e demais funcionários da escola na vida dos alunos, visando construir uma relação de apoio e confiança. Segundo Costa (199I), a Pedagogia da Presença, enquanto teoria que implica os fins e os meios de uma modalidade de ação educativa, que prioriza as ações do educador no educando, implicando um novo caminho para a educação dos jovens de forma emancipadora. 
O último pilar é o Protagonismo Juvenil, sua proposta consiste em promover um ambiente escolar cuidadosamente estruturado para dar oportunidades concretas aos alunos de conquistar a autoconfiança, autodeterminação, autoestima, autonomia, e entre outros elementos imprescindíveis ao gerenciamento de suas habilidades e competências.

O Modelo Pedagógico prevê, na parte Diversificada, a existência da disciplina Projeto de Vida, foco deste artigo, que é contemplada tanto no Ensino Fundamental - Anos Finais como no Ensino Médio. Uma das propostas primordiais do PEI é oferecer e assegurar a construção de um Projeto de Vida. A ideia central do programa é incentivar os jovens a terem um objetivo para suas vidas e dar suporte para que este objetivo seja realmente alcançado, por meio do Projeto de Vida. Neste sentido, cabe ressaltar que o Projeto de Vida é de autoria do aluno, configurando-se em um documento escrito, "[...] que expressa metas e define prazos, com vistas à realização das aptidões individuais, com responsabilidade individual, social e institucional em relação à Escola Estadual do Programa Ensino Integral [...]” (SÃO PAULO - ESTADO, LEI COMPLEMENTAR № I.164, Art. 2, 2012)

Sabendo que a Educação Integral passou a ser um tema com relevância para o contexto atual, e não tão explorado pelas pesquisas acadêmicas, o presente artigo oferece uma contribuição para o tema, buscando explorar as dimensões do Projeto de Vida, dentro da perspectiva do Programa de Ensino Integral. Toma como base, dados bibliográficos a respeito da concepção e desenvolvimento do Projeto de Vida coletados em documentos e em sites oficiais do governo ${ }^{4}$ e, também, dados de uma pesquisa comparativa entre uma escola PEI e outra escola pública não PEI. ${ }^{5}$

\section{PROJETO DE VIDA}

O Projeto de Vida é uma disciplina da parte diversificada do currículo presente nas escolas que aderiram ao Programa de Ensino Integral. É o eixo central do programa, e pressupõe um esforço concentrado da equipe escolar para assegurar seu pleno

\footnotetext{
${ }^{4}$ Diretrizes do Programa Ensino Integral - Caderno do Gestor, material de apoio Projeto de Vida - Caderno do Professor- Ensino Fundamental e Ensino Médio, disponíveis em sites oficiais do governo.

${ }^{5}$ FERNANDES, V. “A formação ética na escola pública: realizações e desafios”. Pesquisa financiada pela Vice-Reitoria de Pós-Graduação e Pesquisa da UNIP, 2020.
} 
desenvolvimento. Esse esforço desdobra-se em diversas atividades presentes em todas as metodologias do Programa, assim, o Projeto de Vida é concebido como “[...] o foco para o qual devem convergir todas as ações educativas do projeto escolar, sendo construído a partir do provimento da excelência acadêmica, da formação para valores e da formação para o mundo do trabalho" (SÃO PAULO - ESTADO, DIRETRIZES DO PROGRAMA ENSINO INTEGRAL, 2012, p. 18).

O Projeto de Vida faz parte da metodologia de projetos, uma aprendizagem ativa de valores e competências para que cada estudante encontre relevância, sentido e propósito no seu processo de aprender e o integre dentro das suas vivências, reflexões, consciência e visão de mundo. A aquisição das aprendizagens oferecidas pela escola ao jovem é um elemento fundamental para a construção e desenvolvimento do Projeto de Vida, pois possibilita seu desenvolvimento acadêmico, pessoal e social, dessa forma:

A elaboração do Projeto de Vida precisa promover, como resultado, um documento original que traduza as especificidades de cada estudante quanto às suas perspectivas, pois, esse tema “(...) nos faz pensar em algo original, dizendo de nossa identidade e da imagem que construímos como sujeitos a partir do que planejamos e realizamos" (PEREIRA e STENGEL, 2015, p. 585).

Ter um Projeto de Vida pressupõe refletir sobre o que se quer ser no futuro e planejar ações concretas para chegar lá. É o caminho entre o querer ser e o ser. Nesse processo, alguns ensinamentos e aprendizagens são importantes, como orientar os alunos sobre perspectivas futuras e viabilizar conhecimentos que irão subsidiar o planejamento e a execução de aprendizagens necessárias para a concretização dos seus objetivos. Em um sentido amplo, é tornar conscientes as aprendizagens, os valores, as competências e as dificuldades, além dos caminhos mais promissores para o desenvolvimento pleno em todas as dimensões

As aulas do Projeto de Vida, são um planejamento de como alcançar o que se deseja para o futuro. Foram elaboradas para levar o estudante a ler o mundo a partir da construção de sua própria identidade, ajudando-o a descobrir e redescobrir o sentido de estudar para alcançar seus objetivos. As escolhas podem ser ampliadas com base nas experiências que cada um tem na vida. Para planejar o futuro é necessário agir no presente, o que significa dar passos concretos em direção ao que se deseja. 
A construção do Projeto de Vida configura-se num dos elementos mais fundamentais da passagem do aluno pelas escolas do PEI, sendo organizado e trabalhado ao longo de todo o ano letivo, com o princípio de levar o aluno a pensar sobre suas intenções e ambições expressas a partir dos seus sonhos. Sendo assim, alguns dos objetivos do Projeto de Vida são:

I. Identificar características da sua personalidade. (Pontos fortes e pontos fracos)

2. Destacar as principais habilidades e interesses.

3. Compreender e relacionar valores pessoais e humanos de atitudes.

4. Estabelecer relações de participação do aluno no contexto familiar, social e cultural. Trabalhar a Convivência social.

5. Trabalhar na criação de visão de futuro e nas expectativas para a vida, estabelecendo objetivos e metas.

6. Trabalhar na associação temporal da visão de futuro e a realidade atual.

7. Estabelecer e validar os conceitos de previsibilidade e antecipar cenários

8. Trabalhar os conceitos de planejamento, execução e organização do tempo. (SÃO PAULO - ESTADO, PROJETO DE VIDA - CADERNO DO PROFESSOR, E.F., 2014, p. 6).

Por meio da mediação de toda unidade escolar para conduzir esses objetivos de forma pedagógica, a disciplina dispõe de um currículo comum, em que conhecimentos, habilidades, atitudes e valores são desenvolvidos de forma intencional e progressiva. Espera-se, dessa maneira, que a disciplina Projeto de Vida contribua para que os estudantes possam:

I. Desenvolver as habilidades e competências do século XXI, previstas nos Quatro Pilares da Educação;

2. Construir e incorporar conhecimentos e valores que permitam a tomada de decisão;

3. Desenvolver a responsabilidade por suas escolhas, compreendendo que as escolhas que fazem na atualidade influenciam o seu futuro;

4. Perceber a importância da escolaridade para que seus planos futuros possam ser realizados;

5. Vislumbrar diferentes cenários e possibilidades para sua formação acadêmica e profissional;

6. Aprender a projetar e traçar caminhos entre o hoje e o amanhã;

7. Colocar em prática todas as possibilidades de vivência do Protagonismo.

8. Construir seu Projeto de Vida.

(SÃO PAULO - ESTADO, PROJETO DE VIDA - CADERNO DO PROFESSOR E.M., 2014, p.5). 
Diante desse processo, durante a constante revisão e construção do Projeto de Vida, espera-se que o estudante obtenha uma formação ética e cidadã, que assegure sua autonomia, solidariedade e competência para agir de forma consciente e transformadora na sociedade, a partir de habilidades obtidas como autoconhecimento, capacidade de planejamento e organização, responsabilidade social, elaboração e gestão de projetos. (Cf. SÃO PAULO - ESTADO, PROJETO DE VIDA -INOVA EDUCAÇÃO, 2012, p. ro).

\section{DESENVOLVIMENTO DO PROJETO DE VIDA}

Ao ingressar no Programa de Ensino Integral os alunos passam por uma atividade denominada Acolhimento, onde são recepcionados por jovens que já passaram pela mesma experiência pedagógica e por meio de dinâmicas em grupo são levados a refletir sobre o que esperam da vida, e ao final dessa atividade cada aluno será capaz de materializar por escrito seu primeiro rascunho de um futuro Projeto de Vida, que será constantemente revisado e contará com o apoio de um professor orientador.

Nesse Acolhimento os alunos são convidados a refletirem sobre o que é ser

perseverante e como vencer os obstáculos, conhecendo quais são os valores, princípios e

premissas do Programa de Ensino Integral de maneira bem lúdica e na linguagem do próprio adolescente. O Acolhimento é a primeira etapa da construção do Projeto de Vida, e em razão disso ele é a primeira atividade pedagogia do ano letivo, sendo uma estratégia na qual são apresentadas aos novos estudantes as bases do projeto escolar, a equipe pedagógica e os ambientes da escola. Essa atividade é o início do compromisso que a escola se coloca à disposição da construção do Projeto de Vida.

Por meio dessa metodologia, os estudantes terão a oportunidade de estabelecer os primeiros vínculos, sentindo-se recebidos e pertencentes à escola desde os primeiros dias de aula. O Acolhimento é um marco inicial da escola na vida dos estudantes que ingressam, por demonstrar desde o início a importância de cada pessoa no processo de construção, autodesenvolvimento e de realização de seu Projeto de Vida, além de garantir a troca de experiências e integração entre todos da escola.

Para a escola, o Acolhimento tem grande importância, pois é por meio dele que toda a equipe escolar tem contato com os primeiros registros dos sonhos dos alunos, que são 
orientados a elaborarem, entre outros, dois importantes documentos que irão direcionar as próximas ações dos educadores, um é a "Cartilha Quem Sou Eu", que é um texto declarativo e reflexivo, que serve para os alunos "[...] pensarem na sua herança social, quais são suas qualidades e defeitos, como ambos podem ser aprimorados, quais são os caminhos que esses jovens precisam traçar para alcançarem seus objetivos tendo em vista sua realidade socioeconômica e cultural". O outro é a "Escada dos Sonhos para o Ensino Fundamental e Escalada do Sonhos para o Ensino Médio - nesse documento os alunos traçam metas temporais para conquistarem seus projetos de vida. (D'AREZZO, 2016, p. 28).

Observa-se que desde o Acolhimento, os estudantes são estimulados a pensar sobre o papel que lhes cabe como protagonistas de suas vidas, como agentes ativos de transformação e renovação da sociedade, aponta-se sobre a necessidade de deixar de ser expectador da vida para ser promotor das próprias ações e a se perceber como fonte de iniciativa, de liberdade e de compromisso. Assim como as aulas do Projeto de Vida, as atividades do Acolhimento abordam questões sobre a construção da identidade dos estudantes e do seu universo de valores na relação consigo mesmo, bem como estimula a reflexão sobre a importância de ter planos e sonhar.

Durante o Acolhimento, a participação da equipe escolar consiste exclusivamente em fornecer apoio relativo aos espaços, materiais, condições de acessibilidade, e se for necessários recursos físicos. Não atua, portanto, na execução e nem na definição dos trabalhos, que são realizados pelos alunos. O Acolhimento é encerrado com as apresentações dos estudantes, através das estratégias definidas por eles próprios (dramatizações, coreografias), expressando sua individualidade para toda a equipe escolar.

É por meio da sistematização dos registros do Acolhimento que a escola elabora as suas principais metas de trabalho, fazendo com que o projeto escolar esteja alinhado com o Projeto de Vida. Esses documentos são entregues à Equipe Gestora que realiza um amplo estudo sobre eles, verificando quais são os Projetos de Vida de seus alunos, em que área de conhecimento se encaixam, traçando objetivos e estratégias de acordo com o perfil dos alunos e seus respectivos Projetos de Vida. A partir daí a escola elabora metas para atingir o Plano de Ação da Escola. Esse plano deverá ser desenvolvido com os alunos em tempo 
integral pelos professores, para que assim, os mesmos possam construir o Programa de Ação dos educadores, o qual deve contemplar todas as ações de cada educador para que a escola caminhe em busca das metas estabelecidas no seu Plano de Ação.

O plano de ação pedagógico é justamente para alinhar o projeto escolar visando a cultura organizacional de ensino com os objetivos e sonhos dos alunos. Através dessa proposta, dinâmicas e atividades são desenvolvidas durante todo o ano letivo, por meio de oficinas, projetos e atividades. Os estudantes vivenciam um processo de reflexão e de experimentação intencional e orientado, o que lhes permite compreender a importância do planejamento para empreender ações em suas vidas e para fazer escolhas baseadas em suas identidades, interesses e valores. O projeto deve acompanhar de várias formas e com diferentes graus de intensidade cada etapa da evolução da criança para a adolescência e juventude, seus novos questionamentos, descobertas e dificuldades. Essa tarefa ocorre por consequência do trabalho desenvolvido nas escolas, que partem dos princípios dos quatro pilares da Unesco - aprender a ser, a fazer, a conhecer e a conviver que se agrupam em três dimensões:

1. Dimensão da Identidade (Eu comigo, aprender a ser): Compreender-se, aceitar-se e saber usar suas habilidades para crescer, realizar-se e buscar o seu bem-estar.

2. Dimensão da Cidadania (Eu com o mundo, aprender a conviver): Relacionar-se de forma harmoniosa e produtiva com as outras pessoas na família, na escola e na comunidade.

3. Dimensão Produtiva (Aprender a fazer): Desenvolver as competências profissionais para empreender e contribuir para uma vida profissional realizadora. (MORAN,2017, p.3)

De acordo com essas dimensões estabelecidas, são estruturados três módulos de ensino: $O$ primeiro módulo tem por finalidade abordar questões relacionadas com a construção da identidade de cada estudante, neste sentido, as aulas são elaboradas com conteúdo que permitem os alunos tomarem maior conhecimento de si, das suas potencialidades e fragilidades e que o auxiliará, uma vez se conhecendo, a posicionar-se em relação aos colegas, familiares e na vida social. O segundo módulo, diz respeito ao comportamento social, ao desenvolvimento de competências para trabalhar em grupo, ser coletivo, aprender a ter uma relação saudável com outros, resolução de conflitos, tomada de decisões, estrutura de valores, respeito às diferenças, com intuito de permitir uma 
interação positiva dos estudantes diante da sociedade. O terceiro e último módulo refere-se a traçar pequenas metas, objetivos e sonhos, para documentá-los de maneira física as vivências e as projeções de suas vidas.

O Ensino Fundamental traça metas anuais até o final do $9^{-0}$ ano, tendo como foco principal a continuidade dos estudos para o próximo ciclo. Para o Ensino Médio as metas têm tempos menores, também visando a continuidade dos estudos, mas com uma perspectiva diferente, tendo como foco, a inserção no mundo do trabalho por meio de uma graduação universitária ou a formação técnica.

No final da segunda série do Ensino Médio, espera-se que os alunos tenham desenvolvido as habilidades essenciais para dar continuidade aos seus estudos e estejam com os seus Projetos de Vidas prontos. Na terceira série, eles têm aulas de Preparação acadêmica e Mundo do Trabalho que nortearão sua inserção no mundo produtivo, seja via profissional ou acadêmica.

O Projeto de Vida construído tem a capacidade de ser um roteiro aberto de autoaprendizagem, multidimensional, em contínua construção e revisão, que pode modificar-se, adaptar-se e transformar-se ao longo de toda a vida de acordo com as experiências e oportunidades vividas. De acordo com o Relatório para a UNESCO: “À educação cabe fornecer, de algum modo, os mapas de um mundo complexo e constantemente agitado e, ao mesmo tempo, a bússola que permite navegar através dele.” (DELORS et. al., 1999, p.98). O Projeto de Vida atua como um mapa para os sonhos e desejos dos alunos, norteando-os como uma bússola em busca do seu futuro.

\section{O IMPACTO DO PROJETO DE VIDA}

Para avaliar o impacto do Projeto de Vida na vida dos alunos, foram comparados alguns dados de formação escolar de uma escola regular com uma escola integrante do PEI, por meio de uma amostra do questionário realizado por FERNANDES (2020) ${ }^{6}$ em sua pesquisa docente, aplicada em 2019.

Cabe salientar que avaliar o impacto do Projeto de Vida na vida dos alunos é uma questão complexa, que envolvem elementos subjetivos e do contexto social de cada aluno,

\footnotetext{
${ }^{6}$ Vide nota 2
} 
assim, busca-se apresentar o impacto construtivista do Projeto de Vida na vida do aluno, comparando uma escola regular com uma escola PEI, para investigar se realmente nas escolas PEI o Projeto de Vida contribuí para orientar e preparar o jovem para o futuro.

\section{Carreira ou profissão que pretende seguir}

Grafico I: Você já pensou e decidiu à carreira ou profissão que pretende seguir? (Escola Regular)

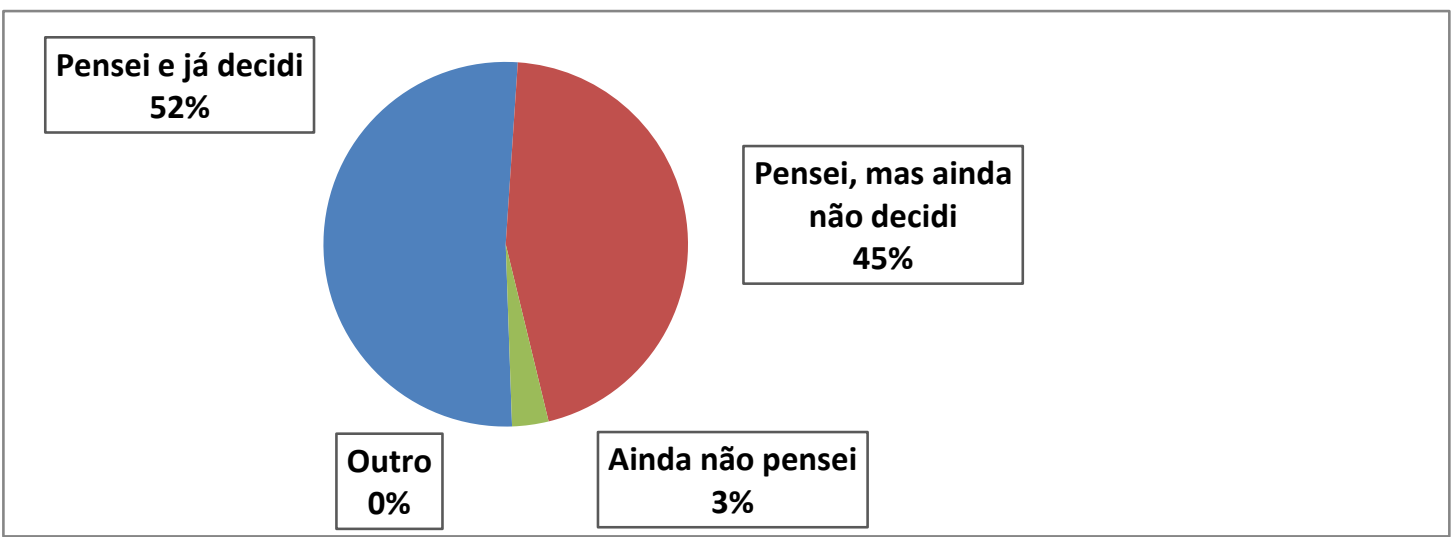

(Fonte: FERNANDES, V. 2020).

Grafico 2: Você já pensou e decidiu à carreira ou profissão que pretende seguir? (Escola PEI)

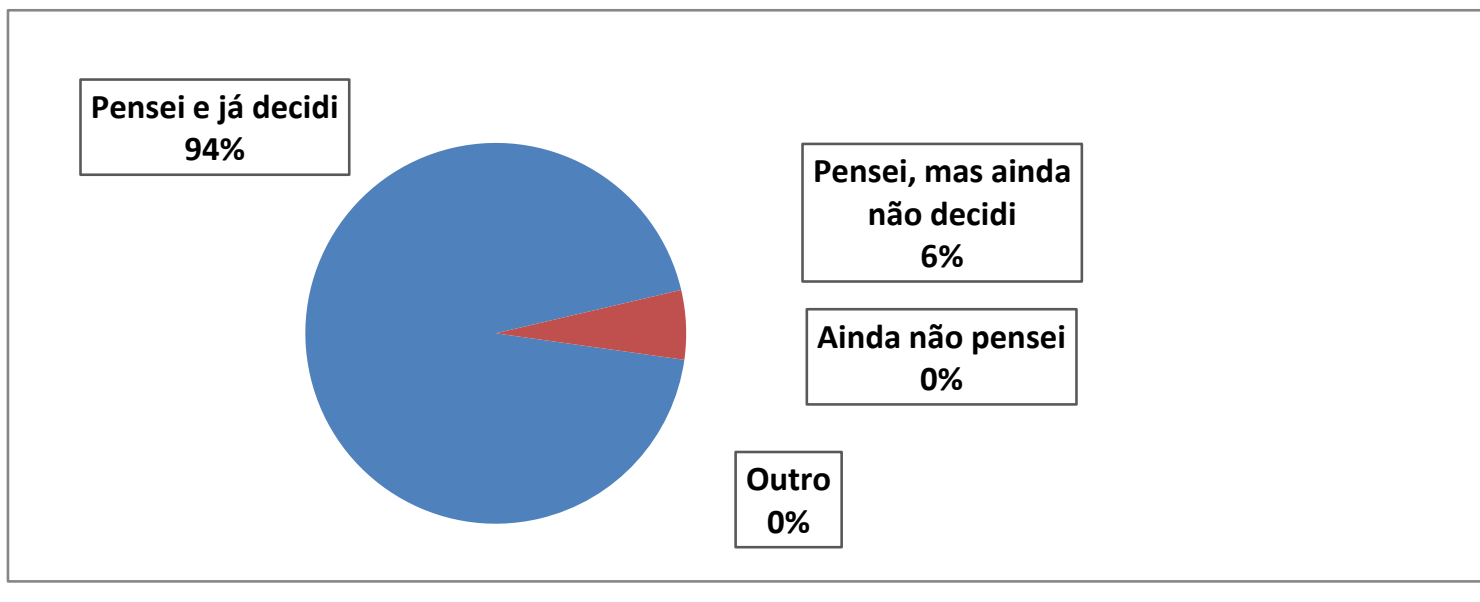

Os gráficos i e 2 dizem respeito a carreira ou profissão que os alunos pretendem seguir, as análises desses dados são fundamentais para evidenciar a distinção do modelo pedagógico em cada escola. Esses gráficos são relevantes para essa pesquisa, por considerar 
o pensamento e a decisão do aluno a respeito da sua profissão que é um aspecto importantíssimo para o seu futuro e objetivo do Projeto de Vida.

Ao observarmos os dados obtidos na escola PEI temos as seguintes informações: 'Pensei e já decide 94\%' e 'Ainda não pensei o\%', por meio desses dados podemos interpretar que os alunos do PEI são estimulados a pensarem sobre suas carreiras e ainda capazes de decidir sobre o seu futuro. O qual não ocorre com tanta asserção nas escolas regulares, visto que apresenta tópicos como 'Ainda não pensei 3\%' e também 'pensei, mas ainda não decidi 45\%', ou seja, é evidente que alguns alunos da escola regular ainda não decidiram ou idealizaram perspectivas futuras de suas vidas, o que é um grande problema para alunos do terceiro ano do ensino médio, que irão concluir a sua formação básica sem a clareza necessária para o ingresso no mundo do trabalho ou na continuação dos seus estudos. Percebe-se que há uma distinção entre esse item em relação as duas escolas analisadas, ${ }^{7}$ isso ocorre por conta do trabalho desenvolvido pelo Projeto de Vida nas escolas PEI, evidenciando que sim o Projeto de Vida de acordo com os dados dessa escola foi capaz de preparar, estimular, apoiar e orientar os jovens a serem protagonistas de sua formação enquanto ser social.

O Programa de Ensino Integral tem promovido uma revisão em muitos paradigmas da Educação, como evidências podemos ver os índices dos resultados do IDESP (Índice de Desenvolvimento da Educação do Estado de São Paulo) referentes ao ano de 2015, que mostram que as escolas de Ensino Médio com jornada expandida tiveram avanço de 64,3\% em quatro anos, o índice saltou de 2,14 para 3,52. Entre as Escolas Regulares, a média foi de 2,25. Também foi constatado que "o ensino integral melhora a aprendizagem dos alunos e aumenta a empregabilidade e renda dos egressos" (SÃO PAULO - ESTADO, 2019).

\section{ESCOLAS DO PEI E O PROJETO DE VIDA: BENEFÍCIOS, LIMITES E POSSIBILIDADES}

\footnotetext{
${ }^{7} \mathrm{O}$ questionário foi aplicado no $2^{\mathrm{o}}$ Semestre de 2019, para alunos do terceiro ano do ensino médio em duas escolas do mesmo bairro da Zona Centro Sul de São Paulo, sendo uma das escolas integrante do Programa de Ensino Integral e outra não integrante, regular normal. Assim, trata-se de um resultado pontual em meio ao universo amplo de escolas existentes e os seus diferentes contextos.
} 
A sociedade mudou de forma acelerada nas últimas décadas, novas configurações nas relações e organizações sociais refletem na formação do indivíduo. Sem dúvida, a escola passou a desempenhar um novo papel na sociedade, o qual vai além da formação acadêmica. Tendo em vista essa mudança, o Programa de Ensino Integral atua como um novo modelo escolar que prioriza a formação de jovens autônomos, solidários e competentes mediante a uma prática educativa eficaz que resulta uma melhoria dos resultados educacionais, uma vez que, o processo de ensino e aprendizagem é realizado por meio da experiência e vivencia de seus alunos, através da elaboração de seus Projetos de Vida.

No estudo realizado ${ }^{8}$ foi possível identificar o compromisso que as escolas do PEI se colocam para garantir o pleno desenvolvimento do Projeto de Vida, evidenciando sua extrema importância no projeto escolar, como norte e eixo estruturante do Programa. Essa importância possui uma extrema relação com as necessidades e dificuldades sociais que a maioria dos alunos da Rede Pública enfrentam, seja em sua formação acadêmica ou profissional. Esta relação parte da defasagem de aprendizagem dos alunos e principalmente da marginalização que os mesmos vivenciam na sociedade por falta de oportunidades. Essa problemática evidencia uma realidade escolar e social, cujo a maioria das classes sociais menos favorecidas sofrem, em alguns casos por diversos motivos, o mais comum é o abandono dos jovens da formação escolar básica, ingressando precocemente no mundo do trabalho, quase sempre em condições de subemprego, com prejuízos para o seu desenvolvimento acadêmico, pessoal, profissional e social.

Tendo em vista essa realidade, o Projeto de Vida pretende se aprofundar e se desenvolver no período da adolescência, que é a fase em que o jovem passa por mais conflitos, é nesse momento de transição que as escolas PEI buscam atuar com alternativas eficazes para uma formação integral. Por essa razão que surge a importância de introduzir o Projeto de Vida no contexto pedagógico das escolas, para a inserção do jovem na sociedade acontecer de forma mais qualificada e menos improvisada. Contudo, pode-se afirmar que o Projeto de Vida prepara, de fato, o jovem para o futuro?

\footnotetext{
${ }^{8}$ Pesquisa de Iniciação Científica. Vide nota I.
} 
Conforme os resultados apresentados ao longo da pesquisa realizada, ${ }^{9}$ é possível destacar como as escolas do PEI contribuem positivamente para garantir a ampliação de oportunidades educacionais e sociais, além de reduzir as taxas de evasão escolar e de defasagem de aprendizado. Uma vez que, conforme se introduz uma prática pedagógica democrática na escola, que vise a formação integral e que se disponha e se preocupe em construir um plano de ação que seja capaz de atender as necessidades e aos interesses dos alunos para a construção de seu desenvolvimento pleno, o resultado esperado é que os jovens comecem a demostrar entusiasmo no seu processo de formação. Segundo Gonçalves (2006), democratizar as relações existentes na escola pressupõe a criação de espaços e situações de aprendizagens que favoreçam compartilhar objetivos, decisões e responsabilidades. Para este autor, tal exercício agregará o aprendizado de um currículo que considere as relações existentes, a participação de todos e a formação de sujeitos críticos e com as competências necessárias para uma atuação social participativa e democrática o que auxilia a construção do Projeto de Vida em conjunto com os princípios norteadores do Programa (A Educação Interdimensional; Os Quatro Pilares da Educação; A Pedagogia da Presença e o Protagonismo Juvenil).

A estrutura curricular da disciplina Projeto de Vida é dividia em módulos que se fundamentam nos Quatro Pilares da Educação, pilares fundamentais para o desenvolvimento do Projeto de Vida, uma vez que, priorizam as aprendizagens essenciais para a toda vida, sendo utilizados como pilares do conhecimento. O primeiro pilar do aprender a conhecer é o objetivo inicial do Projeto de Vida, que busca oferecer diversas oportunidades educacionais para que o jovem aprenda a aprender e a se conhecer, para assim desenvolver as habilidades e competências necessárias para a sua formação, posteriormente é dado andamento no pilar do aprender a conviver, para que o aluno com seu progresso intelectual seja capaz de se relacionar com o próximo e a conviver em harmonia em constante transformação social. Daí surge o pilar do aprender a fazer, saber agir de forma consciente no meio envolvente, contribuindo com ações sociais de caráter coletivo e benéfico a todos. E por fim, o objetivo primordial da construção do Projeto de Vida que é o pilar do aprender a ser, que interage com todos os outros pilares em uma perspectiva de

\footnotetext{
${ }^{9}$ Vide nota I
} 
formação autônoma, solidaria e competente, com o princípio do desenvolvimento da identidade e da cidadania.

Uma educação que visa o desenvolvimento integral do aluno em construção com um Projeto de Vida em andamento se relaciona também com a proposta de educação Interdimensional, na qual se expande para além do paradigma racional e cognitivo, atingindo e aprimorando diversas dimensões da vida em sociedade dentro do contexto pedagógico. A sociedade está em constante modernização, e a escola como ambiente de "preparo" para a vida em sociedade deve se adaptar para exercer sua função formativa nos indivíduos nela presentes, mas somente uma formação acadêmica não é mais suficiente para atender as demandas da sociedade contemporânea, que exige cada vez mais preparo dos jovens, sendo necessária uma formação interdimensional, que relacione a formação acadêmica com a pessoal e social, de forma que o jovem possa desenvolver suas várias potencialidades e dimensões de forma integrada.

Esse preparo é oferecido e garantido pelo Projeto de Vida, pois ao atuar com a função de orientar o jovem sobre perspectivas futuras é preciso atuar com o jovem aprendizagens, habilidades e competências para subsidiar o futuro desejado. A disciplina Projeto de Vida também conta com o apoio do Protagonismo Juvenil, um dos princípios do Programa de Ensino Integral, que visa a atuação do jovem como personagem principal para a resolução de problemas, sua participação ativa e construtiva sobre a sociedade. Desenvolvendo aptidões como: autonomia, autoestima, autodeterminação e entre outras fundamentais para o seu sucesso escolar e profissional.

O Programa de Ensino Integral oferece alternativas e soluções para o desafio de se obter uma educação de qualidade, contando com uma gestão, currículo e espaços diferenciados, os quais favorecem para uma aprendizagem de qualidade através de oficinas e vivencias, desenvolvendo diversas competências e habilidades como o empreendedorismo pessoal, autoconhecimento e a transformação de sonhos em metas e realizações, buscando sempre a interação com a sociedade e suas mazelas. Assim, espera-se que com a construção do Projeto de Vida, os jovens sejam capazes de alavancar a vida acadêmica e profissional, diminuindo a injustiça social em relação à continuidade dos estudos e na carreira profissional, e principalmente, apoiar os jovens para que não desistam 
de seus sonhos em relação ao futuro, orientando caminhos e formas para que os mesmos sejam felizes em suas escolhas. Mas seria o Projeto de Vida uma ação pedagógica acessível para todos ou privilégio de poucos?

Segundo artigo de Girotto \& Cássio (2018), as propostas do PEI em consonância com as políticas públicas de educação apresentam resultados que indicam a reprodução da desigualdade educacional, sob uma perspectiva de produzir unidades escolares destinadas a alunos já privilegiados em suas relações com a cidade. Essa questão levantada, dificulta a construção de políticas públicas equitativas, ampliando a desigualdade educacional pela exclusão de estudantes e pela mudança do perfil socioeconômico das unidades escolares. $\mathrm{O}$ direito à educação pressupõe a necessidade de acompanhamento e avaliação constante das políticas públicas, a fim de compreender os seus princípios norteadores e as implicações sobre a dinâmica social. De acordo com o panorama das implicações do PEI na educação pública paulista, Vieira (2016) aponta que:

\footnotetext{
A diversificação da oferta pode, por um lado, atender a demandas específicas, mas também pode, por outro lado, acentuar desigualdades. Aqueles que financeiramente podem e querem se dedicar só aos estudos, preparando-se para o ingresso no ensino superior, estão no integral; já aqueles que precisam conciliar os estudos com o trabalho, seja por necessidades econômicas, individuais e/ou familiares, costumam frequentar o período parcial, especialmente no noturno ou na Educação de Jovens e Adultos (EJA). (APUD, GIROTTO \& CÁSSIO, 2018, P. 9)
}

Essa teoria de manutenção das desigualdades educacionais se sustenta, perante a localização e distribuição das escolas PEI em áreas de baixa vulnerabilidade social e com menores taxas de analfabetismo. Além do que, as escolas PEI se comparadas às unidades escolares do entorno e à própria rede estadual, possuem menos classes e matrículas, ou seja, são escolas destinadas para poucos. (CF. GIROTTO \& CÁSSIO, 20I8). Dessa forma, não se pode ignorar que o sistema educacional brasileiro é desigual e o PEI se inscreve dentro desta lógica, apresentando vantagens e desvantagens para o cenário da educação pública. A diminuição das desigualdades educacionais só ocorrerá de fato com a elaboração e implantação de políticas públicas consistentes de médio e longo prazo, tendo como prioridade e comprometimento promover uma educação de qualidade e com equidade.

Assim, os alunos que tem a oportunidade de estudar em uma unidade escolar PEI, são privilegiados com uma ação pedagógica como o Projeto de Vida, uma vez que, diante 
das oportunidades que surgem no cotidiano escolar dos alunos, os jovens serão capazes de compreender as exigências da sociedade contemporânea, perante aquisição de conhecimentos e o desenvolvimento de competências e habilidades específicas asseguradas a partir das ofertas de condições para a construção de seus Projetos de Vida, concebidos por meio da formação de valores e da formação para o mundo do trabalho. A disciplina Projeto de Vida traz sentido e significado para a vida escolar, os alunos começam a relacionar seu progresso acadêmico com sua realização pessoal e percebem serem capazes de consolidar seus sonhos por meio das vivências e aprendizagens adquiridas na escola, além do mais tornam-se agentes transformadores em nossa sociedade.

Dessa forma, quanto mais avançarmos em uma pedagogia que valoriza as diferentes dimensões do conhecimento, os valores da comunidade e dos alunos, mais cidadãos conscientes iremos ter em nossa sociedade, desta maneira promover na escola uma educação de formação integral é um objetivo que pode ser alcançado e o Projeto de Vida é um meio para isso.

\section{CONSIDERAÇÕES FINAIS}

Este artigo apresenta e discute a proposta e o desenvolvimento do Projeto de vida, com intuito de compreender se o Projeto de Vida, enquanto eixo central das escolas do PEI, contribui de forma efetiva para a aquisição de habilidades e competências necessárias para a formação do jovem do século XXI.

Atualmente, a escola não tem conseguido atender as necessidades de formação dos jovens para a sua inserção no mundo moderno, que exige habilidades complexas e autonomia pessoal. Além das defasagens de aprendizagem, os estudantes concluem a Educação Básica sem perspectivas pessoais e/ou profissionais, para dar continuidade aos estudos e escolher uma carreira. A construção de um Projeto de Vida contribui para o engajamento dos jovens nos estudos e ajuda nas escolhas que farão para o seu futuro. $\mathrm{O}$ trabalho com o Projeto de Vida traz sentido e significado para a vida escolar, pois desenvolve atividades intencionais, planejadas e monitoradas em consonância com as necessidades, sonhos, desejos e realidade dos alunos. 
Em um mundo multicultural, permanentemente conectado e em profunda transformação, é fundamental investir em uma educação baseada em valores, desenvolvimento de competências e aprendizagem por projetos, integrados ao Projeto de Vida, que prepare o jovem para consolidar seus objetivos e definir suas perspectivas futuras. Dessa forma, ao refletir que não é o tempo que o jovem fica na escola que faz a diferença em sua formação, mas sim o comprometimento de uma formação integral vinculada a continuidade dos estudos e escolha profissional, que contribuirá verdadeiramente na formação da cidadania, autonomia, solidariedade e habilidades dos jovens, a partir da construção de um Projeto de Vida que lhe permite decidir sobre seu próprio futuro.

As diretrizes das escolas do PEI, visam garantir o desenvolvimento pleno a todos os estudantes, considerando o aspecto intelectual, o sócio emocional, o físico e cultural. Pretendem reduzir a evasão escolar, melhorar o engajamento dos estudantes e o clima nas escolas, fortalecer a ação docente e o vínculo entre os professores e alunos, além de diminuir a defasagem de aprendizado. Esses aspectos contribuem para uma organização escolar voltada para a realidade dos alunos, preparando-os para construir seus projetos de vida e serem protagonistas de sua formação.

Como dizia Paulo Freire (200o, p. 33): "se, na verdade, não estou no mundo para simplesmente a ele me adaptar, mas para transformá-lo; e não é possível mudá-lo sem um certo sonho ou projeto de mundo", ou seja, cabe a escola oferecer as oportunidades e possibilidades para seus alunos planejem e realizem seus sonhos e objetivos, tornando-se protagonistas de sua própria história e agentes transformadores em nossa sociedade. Sendo assim, é necessário que essas oportunidades não fiquem reduzidas a uma minoria de alunos, em apenas um percentual pequeno de escolas da rede pública. Neste sentido, espera-se que as análises e reflexões realizadas neste artigo ajudem a fomentar a discussão sobre o tema e, também, que novos estudos a respeito das Escolas do PEI e sobre o Projeto de Vida sejam constituídos, de tal forma que possam contribuir para o aperfeiçoamento e a ampliação desta modalidade de educação. 


\section{REFERÊNCIAS BIBLIOGRÁFICAS}

BRASIL. LDB (1996). Lei de Diretrizes e Bases da Educação Nacional: no 9394/96. Brasília: 1996. i2.ed. Atualizada até o8/o6/2or6.

COSTA, Antônio. Carlos. Gomes. Educação uma Perspectiva para o Século XXI. Canção Nova, 2008.

COSTA, Antônio Carlos Gomes. Por Uma Pedagogia da Presença. Brasília: Editora: Ministério da Ação Social, I99I.

D' AREZZO, Adriana Maria. A formação do Professor Protagonista no Programa Ensino Integral do Estado de São Paulo. São Carlos - SP. 2016.

DELORS, Jacques. et. al. Educação: um tesouro a descobrir. Relatório para a UNESCO da Comissão Internacional sobre Educação para o século XXI. São Paulo: Cortez, 2003.

FERNANDES, Vladimir. "A formação ética na escola pública: realizações e desafios". Pesquisa financiada pela Vice-Reitoria de Pós-Graduação e Pesquisa da UNIP, 2020.

FREIRE, P. Pedagogia da Indignação: cartas pedagógicas e outros escritos. São Paulo: Editora UNESP, 2000 .

GIROTTO, Eduardo Donizeti \& Cássio, Fernando Luiz. (2018). A desigualdade é a meta: Implicações socioespaciais do Programa Ensino Integral na cidade de São Paulo. Arquivos Analíticos de Políticas Educativas, 26(Io9). http://dx.doi.org/ıo.14507/epaa.26.3499 Acesso em: 16 nov. 2020.

GONÇALVES, Antônio Sergio. Reflexões sobre educação integral e escola de tempo integral, 2006.

PEREIRA, Heloisa Cristina \& STENGEL, Marcia. Projetos de vida na Pós-Modernidade: possibilidades e limites aos jovens. Psicologia em Revista, Belo Horizonte, v. 2I, n. 3, p.582598, dez. 2015.

QUARESMA, Daniel Genili. Gestão Democrática na escola de Ensino Integral: Limites e possibilidades. 2015.

SÃO PAULO (Estado). Diretrizes do Programa Ensino Integral. Secretaria de Estado da Educação, Imprensa Oficial, 2012.

SÃO PAULO (Estado). Diretrizes do Programa Ensino Integral - Caderno do Gestor. Secretaria de Estado da Educação, Imprensa Oficial, 2oi4.

SÃO PAULO (Estado). Secretaria de Estado da Educação. Projeto de Vida - Ensino Fundamental. Caderno do Professor. São Paulo. Imprensa Oficial, SE, 2014.

SÃO PAULO (Estado). Secretaria de Estado da Educação. Projeto de Vida - Ensino Médio. Caderno do Professor. São Paulo. Imprensa Oficial SE, 2014.

SÃO PAULO (Estado). Lei Complementar no I.I64, de 4 de janeiro de 2012. Diário Oficial do Estado de São Paulo, seção I, p. I, 5 jan. 2012. Disponível em: http://www.legislacao.sp.gov.br/legislacao/dg280202.nsf/589653dao6ad8eoa83256cfboo50I4 6b/73994a487dbodf348325797coo4a5694?OpenDocument. Acesso em: II fev. 2019.

TENÓRIO, Alier Ferraz \& SCHELBAUER, Analete Regina. A defesa pela educação integral na obra de Anísio Teixeira. In: Biblioteca virtual de Anísio Teixeira, 2007.

VOORWALD, Herman Jacobus Cornelis \& SOUZA, Valeria. O novo modelo de escola de tempo integral: Programa Ensino Integral. Secretaria da Educação. São Paulo, SE, 2014. 